\title{
Comparison of Pharmacokinetics and Safety of Voriconazole Intravenous-to-Oral Switch in Immunocompromised Children and Healthy Adults ${ }^{\nabla}$
}

\author{
Timothy A. Driscoll, ${ }^{1}$ Lolie C. Yu, ${ }^{2}$ Haydar Frangoul, ${ }^{3}$ Robert A. Krance, ${ }^{4}$ Eneida Nemecek, ${ }^{5}$ \\ Jeffrey Blumer, ${ }^{6}$ Antonio Arrieta, ${ }^{7}$ Michael L. Graham, ${ }^{8}$ Scott M. Bradfield, ${ }^{9}$ \\ Alice Baruch, ${ }^{10}$ and Ping Liu ${ }^{11 *}$ \\ Department of Pediatrics and Duke Clinical Research Institute, Duke University, Durham, North Carolina ${ }^{1}$; Children's Hospital/LSUHSC, \\ New Orleans, Louisiana ${ }^{2}$; Pediatric Blood and Marrow Transplant Program and Vanderbilt University Medical Center, Nashville, \\ Tennessee ${ }^{3}$; Texas Children's Hospital, Houston, Texas ${ }^{4}$; Pediatric Bone Marrow Transplant Program, Doernbecher Children's \\ Hospital and Oregon Health \& Science University, Portland, Oregon ${ }^{5}$; University Hospitals Case Medical Center, Cleveland, \\ Ohio ${ }^{6}$; Children's Hospital of Orange County, Orange County, California ${ }^{7}$; Pediatric Bone Marrow Transplant Program and \\ University of Arizona Health Sciences Center, Tucson, Arizona ${ }^{8}$; Nemours Children's Clinic_Jacksonville and \\ Pediatrics of Mayo Clinic College of Medicine, Jacksonville, Florida ${ }^{9}$; Clinical Affairs, Specialty Care, \\ Pfizer Inc., New York, New York ${ }^{10}$; and Clinical Pharmacology, \\ Specialty Care, Pfizer Inc., Groton, Connecticut ${ }^{11}$
}

Received 19 April 2011/Returned for modification 9 September 2011/Accepted 25 September 2011

\begin{abstract}
Voriconazole pharmacokinetics are not well characterized in children despite prior studies. To assess the appropriate pediatric dosing, a study was conducted in 40 immunocompromised children aged 2 to $<12$ years to evaluate the pharmacokinetics and safety of voriconazole following intravenous (IV)-to-oral (PO) switch regimens based on a previous population pharmacokinetic modeling: $7 \mathrm{mg} / \mathrm{kg}$ IV every $12 \mathrm{~h}(\mathrm{q} 12 \mathrm{~h})$ and $200 \mathrm{mg}$ PO $q 12 \mathrm{~h}$. Area under the curve over the 12-h dosing interval $\left(\mathrm{AUC}_{0-12}\right)$ was calculated using the noncompartmental method and compared to that for adults receiving approved dosing regimens $(6 \rightarrow 4 \mathrm{mg} / \mathrm{kg} \mathrm{IV} \mathrm{q12h,} 200$ mg PO q12h). On average, the $\mathrm{AUC}_{0-12}$ in children receiving $7 \mathrm{mg} / \mathrm{kg}$ IV q12h on day 1 and at IV steady state were 7.85 and $21.4 \mu \mathrm{g} \cdot \mathrm{h} / \mathrm{ml}$, respectively, and approximately $44 \%$ and $40 \%$ lower, respectively, than those for adults at $6 \rightarrow 4 \mathrm{mg} / \mathrm{kg}$ IV q12h. Large intersubject variability was observed. At steady state during oral treatment $(200 \mathrm{mg} \mathrm{q12h}$ ), children had higher average exposure than adults, with much larger intersubject variability. The exposure achieved with oral dosing in children tended to decrease as weight and age increased. The most common treatment-related adverse events were transient elevated liver function tests. No clear threshold of voriconazole exposure was identified that would predict the occurrence of treatment-related hepatic events. Overall, voriconazole IV doses higher than $7 \mathrm{mg} / \mathrm{kg}$ are needed in children to closely match adult exposures, and a weight-based oral dose may be more appropriate for children than a fixed dose. Safety of voriconazole in children was consistent with the known safety profile of voriconazole.
\end{abstract}

Voriconazole is a broad-spectrum triazole antifungal agent with activity against a wide range of yeasts and filamentous fungi $(2,4,5,11)$. Voriconazole is approved for the primary treatment of acute invasive aspergillosis (IA) and as a salvage therapy for serious fungal infections caused by rare molds such as Scedosporium and Fusarium species in adults, as well as for the treatment of Candida infections in nonneutropenic adults (12). Multiple dosing regimens have been approved to treat these infections. Voriconazole is extensively metabolized by and is also an inhibitor of the cytochrome P450 (CYP) isozymes CYP2C19, CYP2C9, and CYP3A4, which results in extensive drug interactions with concomitant mediations. Voriconazole exhibits nonlinear pharmacokinetics due to saturation of its metabolism. In adults, intersubject variability in voriconazole exposure is high, and CYP2C19 genotype, gender, and age are key factors which help explain this variability.

* Corresponding author. Mailing address: Clinical Pharmacology, Specialty Care, Pfizer Inc., 445 Eastern Point Road, MS8260-2509, Groton, CT 06340. Phone: (860) 441-8269. Fax: (860) 686-5648. E-mail: ping.liu@pfizer.com.

${ }^{\nabla}$ Published ahead of print on 3 October 2011.
Because of the significant clinical benefit of voriconazole for IA treatment in adults (6), the use of voriconazole as an option in pediatric patients has increased significantly. However, the pharmacokinetics of voriconazole have not been well characterized in children aged 2 to $<12$ years despite several prior pharmacokinetic studies $(8,15,16)$. Different intravenous (IV) and oral (PO) maintenance doses (i.e., 3, 4, 6, 7 and $8 \mathrm{mg} / \mathrm{kg}$ IV every $12 \mathrm{~h} \mathrm{[q12h];} 4$ and $6 \mathrm{mg} / \mathrm{kg}$ PO q12h) have been evaluated. It has been demonstrated that the nonlinearity of voriconazole pharmacokinetics in children is less pronounced than in adults, and larger intersubject variability in exposure is observed in children $(8,15,16)$. It has been shown that $4 \mathrm{mg} / \mathrm{kg}$ IV $\mathrm{q} 12 \mathrm{~h}$ is needed in children to provide voriconazole exposure comparable to that achieved in adults with $3 \mathrm{mg} / \mathrm{kg}$ IV $\mathrm{q} 12 \mathrm{~h}$ (16). However, there is no consensus on the pediatric doses that match the exposures in adults receiving other approved dosing regimens (e.g., a 6-mg/kg IV loading dose, 4 $\mathrm{mg} / \mathrm{kg}$ IV q12h, and $200 \mathrm{mg}$ PO q12h). Using noncompartmental-analysis results, one study (15) suggested $8 \mathrm{mg} / \mathrm{kg}$ IV q12h and another recent study (8) suggested $7 \mathrm{mg} / \mathrm{kg}$ IV q12h in children in order to match $4 \mathrm{mg} / \mathrm{kg}$ IV $\mathrm{q} 12 \mathrm{~h}$ in adults. A 
previous population pharmacokinetic modeling and simulation based on the pooled data from previous pediatric pharmacokinetic studies proposed the following: no IV loading doses are required in children, since the predicted exposure of $7 \mathrm{mg} / \mathrm{kg}$ IV on day 1 is not notably lower than that in adults at $6 \mathrm{mg} / \mathrm{kg}$ IV on day $1 ; 7 \mathrm{mg} / \mathrm{kg}$ IV q12h in children would match $4 \mathrm{mg} / \mathrm{kg}$ IV q12h in adults; and the same oral regimen of $200 \mathrm{mg}$ PO q12h could be used in children and adults (7). However, the use of modeling to support voriconazole pediatric dosing regimens has not been widely accepted by regulatory agencies.

Since there is an unmet medical need in children with invasive fungal infections, it is imperative to identify the appropriate voriconazole pediatric dosing regimen. In this pediatric study, the primary objective was to characterize the pharmacokinetics and safety of voriconazole in children 2 to $<12$ years old receiving the proposed IV-to-PO switch regimens based on the previous modeling and to assess if these are appropriate to match the approved adult dosing regimens. In addition, the potential effect of CYP2C19 genotyping status on voriconazole pharmacokinetics in children was evaluated.

(Some of the data in this article were presented as an abstract and poster presentation at the 50th Interscience Conference on Antimicrobial Agents and Chemotherapy, Boston, MA, Sept. 12 to 15,2010 .)

\section{MATERIALS AND METHODS}

Study design. (i) Study A (children). Study A was an open-label, voriconazole IV-to-PO switch, multiple-dose, multicenter study in immunocompromised children aged 2 to $<12$ years who were at high risk for systemic fungal infection. This study consisted of an initial pharmacokinetic period (voriconazole, $7 \mathrm{mg} / \mathrm{kg} \mathrm{IV}$ $\mathrm{q} 12 \mathrm{~h}$ for 7 days followed by $200 \mathrm{mg}$ PO q12h for 6.5 days; extended IV treatment up to 20 days was allowed), followed by an optional nonpharmacokinetic period if clinically indicated (voriconazole administration could be continued up to day 30 ), with a 1-month follow-up after the last dose of study drug. In special cases, the subject was permitted to receive voriconazole more than 30 days to allow for scheduling of serial pharmacokinetic sampling in order to maximize the feasibility of the study's completion. Sixteen study centers in the United States participated in this study, and this study was approved by the local institutional review boards. Written informed consent and assent (for children who could comprehend the information) were obtained prior to the subject entering the study.

(ii) Study B (adult reference). In order to provide robust adult reference data for comparison, a pharmacokinetic study in healthy adults was conducted in parallel at Pfizer Clinical Research Unit in Brussels, Belgium. Subjects received voriconazole $6 \mathrm{mg} / \mathrm{kg} \mathrm{IV} \mathrm{q12h}$ on day 1 followed by $4 \mathrm{mg} / \mathrm{kg} \mathrm{IV} \mathrm{q12h}$ for the next 6 days and then were switched to $200 \mathrm{mg}$ PO q12h for 6.5 days. This study was approved by the local independent ethics committee. Written informed consent was obtained prior to the subject entering the study.

Study population. (i) Study A. Male or female children from 2 to $<12$ years of age who required systemic antifungal prophylaxis and were anticipated to tolerate oral therapy after 7 to 20 days of parenteral voriconazole were eligible for the study. Subjects were expected to develop neutropenia (absolute neutrophil count $<500$ cells $/ \mu \mathrm{l}$ ) lasting more than 10 days following chemotherapy for leukemia, lymphoma, or aplastic anemia or as a hematopoietic stem cell transplant (HSCT)-preparative regimen. Subjects were excluded if they had known hypersensitivity to azoles, abnormal laboratory safety findings at screening [aspartate aminotransferase (AST) or alanine aminotransferase (ALT) $>5$ times the upper limit of normal (ULN) or total bilirubin $>2.5$ times the ULN], moderate or severe renal impairment (i.e., estimated creatinine clearance $<50$ $\mathrm{ml} /$ minute), prior or current evidence of cardiac arrhythmia, or any condition possibly affecting drug absorption (e.g., gastrectomy). Subjects were excluded if they were receiving inhibitors of CYP450 enzymes that affect voriconazole exposure (e.g., fluconazole, itraconazole, posaconazole, or omeprazole) or drugs with potential QT interval prolongation (e.g., terfenadine, astemizole, cisapride, pimozide, or quinidine) within $24 \mathrm{~h}$ prior to study start, or anticipated to receive any of these drugs during the study. Subjects were excluded if they were receiving inducers of CYP450 enzymes (e.g., rifampin, rifabutin, carbamazepine, pheny- toin, nevirapine, long-acting barbiturates, efavirenz, and ritonavir) within 14 days prior to study start or were expected to receive any of these drugs during the study. Subjects were excluded if they would need to receive any other drugs prohibited in the voriconazole product label during the study (e.g., sirolimus and ergot alkaloids). Subjects were also excluded if they had any other condition which, in the opinion of the investigator, made the subject unsuitable for enrollment.

(ii) Study B. Study B included healthy nonsmoking male and female subjects, aged 18 to 55 years and weighing between 40 and $100 \mathrm{~kg}$. Health status was determined by a detailed medical history, full physical examination, including vital signs, 12-lead electrocardiograms (ECGs), and safety laboratory tests. Subjects were excluded if they had known hypersensitivity to azoles, positive urine drug screenings, or evidence of liver disease. Subjects were prohibited from use of prescription or nonprescription drugs and dietary supplements within 7 days or 5 half-lives (whichever was longer) prior to the first dose of study drug. As an exception, acetaminophen/paracetamol could be used at doses of $\leq 1 \mathrm{~g} / \mathrm{day}$.

Study treatment. In both studies, all IV voriconazole doses were administered at an infusion rate of approximately $3 \mathrm{mg} / \mathrm{kg} / \mathrm{h}$ (i.e., the 7-, 6-, and 4-mg/kg doses were administered by infusion over 140,120 , and $80 \mathrm{~min}$, respectively). The 200-mg oral voriconazole dose was administered at least $1 \mathrm{~h}$ before or after meals (as food intake decreases voriconazole exposure during oral administration) Regarding the oral formulations, an oral suspension was used in children and a tablet was used in adults. Both IV and oral voriconazole were administered every $12 \mathrm{~h} \pm 30 \mathrm{~min}$.

Pharmacokinetic sampling. (i) Study A (children). A total of 27 blood samples (1 to $2 \mathrm{ml}$ per sample to provide approximately $0.5 \mathrm{ml}$ plasma) were to be collected from each subject. Specifically, on days 1 and 7 of IV treatment, plasma samples were collected predosing and at $60 \mathrm{~min}, 138 \mathrm{~min}$ ( $2 \mathrm{~min}$ prior to the end of infusion), $4 \mathrm{~h}, 6 \mathrm{~h}, 8 \mathrm{~h}$, and $12 \mathrm{~h}$ after the start of infusion; on the 7th day of oral dosing, samples were collected predosing and at $1,2,4,6,8$, and $12 \mathrm{~h}$ after dosing. Additionally, plasma samples were taken just prior to dosing (trough sample) on the 4th through the 6th day of IV and oral dosing. An alternative pharmacokinetic sampling schedule (a total of 19 samples) was applied to a few younger children when there was a concern about the blood volume to be collected: on days 1 and 7 of IV treatment, predosing and $138 \mathrm{~min}, 5 \mathrm{~h}, 8 \mathrm{~h}$, and $12 \mathrm{~h}$ after the start of infusion; on the 7th day of oral treatment, predosing and at $2,5,8$, and $12 \mathrm{~h}$ after dosing. A trough sample was collected on the 5 th and 6 th days of IV and oral treatment, respectively. If subjects could not be scheduled for serial sampling on the 7 th day of IV or oral dosing, subjects could remain on IV or oral treatment to allow sample collection at a later day.

(ii) Study B (adults). A total of 23 blood samples were to be collected from each subject. Specifically, on day 1 of IV treatment, samples were collected predosing and at $60 \mathrm{~min}, 118 \mathrm{~min}, 4 \mathrm{~h}, 6 \mathrm{~h}, 8 \mathrm{~h}$, and $12 \mathrm{~h}$ after the start of infusion; on day 7 of IV treatment, samples were collected predosing and at $40 \mathrm{~min}, 78$ $\min , 4 \mathrm{~h}, 6 \mathrm{~h}, 8 \mathrm{~h}$, and $12 \mathrm{~h}$ after the start of infusion; on the 7 th day of oral treatment (day 14), samples were collected predosing and at 1, 2, 4, 6, 8, and $12 \mathrm{~h}$ after dosing. A trough sample was collected on the 6th day of IV and oral treatment, respectively.

Analytical methods. PPD Development (Richmond, VA) analyzed all the plasma samples using a previously validated liquid chromatography coupled to tandem-mass spectrometry (LC-MS/MS) method (1). The plasma samples $(0.100$ $\mathrm{ml}$ ) were extracted using a solid-phase extraction procedure followed by LC MS/MS separation and detection. The dynamic range of the assay for voriconazole was 10 to $5,000 \mathrm{ng} / \mathrm{ml}$. In study A, the accuracy of the quality control samples used during sample analysis ranged from $0.514 \%$ to $3.06 \%$ with a precision of $\leq 7.36 \%$. In study $\mathrm{B}$, the accuracy of the quality control samples ranged from $-1.80 \%$ to $1.75 \%$ with a precision of $\leq 7.84 \%$. All the samples were analyzed within an established long-term stability period.

Pharmacokinetic analysis. Noncompartmental pharmacokinetic analysis was performed using the internally validated system eNCA v2.2.1. Maximum plasma concentration $\left(C_{\max }\right)$, time to reach $C_{\max }$, and trough concentration $\left(C_{\min }\right)$ for voriconazole were estimated directly from concentration-time data. The area under the concentration-time curve over a 12-h dosing interval $\left(\mathrm{AUC}_{0-12}\right)$ for voriconazole was estimated using the linear/log trapezoidal approximation. The achievement of steady state was assessed by visual inspection of trough concentrations. Samples below the lower limit of quantification were set to $0 \mathrm{ng} / \mathrm{ml}$ for analysis. Actual sample collection times were used for the pharmacokinetic analysis.

CYP2C19 genotyping. Buccal swab samples were collected from children instead of whole blood, since many subjects had leukopenia secondary to chemotherapy. The buccal samples were analyzed for CYP2C19 genotyping at Pfizer Pharmacogenomics Laboratory (Groton, CT). Genomic DNA was purified using a QIAamp DNA minikit (Qiagen). Five single-nucleotide polymorphisms for 
CYP2C19, $* 2, * 3, * 4, * 5$, and $* 17$, were analyzed. Ultrarapid extensive metabolizer (UM) was defined as *17, *17. Homozygous extensive metabolizer (EM) was defined as * 1 , *1. Poor metabolizer (PM) was defined as *2, *2. Heterozygous extensive metabolizer (HEM) was defined as any combination of two of the above (e.g., $\left.{ }^{*} 1,{ }^{*} 2 ; * 2,{ }^{*} 17\right)$. Whole-blood samples were collected from adults and were analyzed at Gentris (Morrisville, $\mathrm{NC}$ ).

Safety assessment. Adverse events (AEs) were monitored closely throughout the study. In study A (children), safety laboratory tests, testing of vital signs, and physical examinations were performed at screening, on day 1 of IV treatment (prior to dosing), the 1st day of oral treatment, every 5 to 7 days during the study treatment period, and at the 1-month follow-up visit. Extra efforts were made to monitor potential visual side effects of voriconazole. Visual assessments (visual questionnaire, distance visual acuity testing, and color vision testing) were performed in children older than 5 years or as developmentally appropriate on day $1 \mathrm{IV}$, the 1 st day of oral treatment, every 5 to 7 days during the study treatment period, and at the follow-up visit. In the younger children, who were unable to follow the instructions, visual fixation was tested. In addition, single 12-lead ECGs were collected at screening, on days 1 and 7 of IV treatment, and on the 1st and 7th day of oral treatment. In study B (adults), safety laboratory tests, testing of vital signs, physical examinations, and visual assessments were performed at screening and on days 0,7 , and 14 .

For both studies, if a change in visual acuity or the color vision test from the baseline was noted and/or the subject reported any new visual symptoms, a formal ophthalmologic examination (dilated fundoscopy) was performed to evaluate the significance of the findings.

The safety data from study B are not presented in this article, as the study's objective was the comparison of voriconazole exposure in children to that in adults.

Statistical analysis. A sample size of 30 children for study A was chosen based on the need to minimize exposure to this special population and the requirement to provide adequate pharmacokinetic, safety, and tolerability information. Assuming an $18 \%$ dropout rate, it was decided that 36 subjects should participate to ensure that at least 30 subjects completed the pharmacokinetic period. Accordingly, a sample size of 30 adults in study B was chosen to match study A. All the data were summarized with descriptive statistics, and no formal inferential statistics were applied.

Voriconazole pharmacokinetic parameters were evaluated by gender, age, body weight, and CYP2C19 genotyping status. Given the large intersubject variability in voriconazole exposure and the limitation of sample size, an informal statistical comparison of exposure parameters $\left(\mathrm{AUC}_{0-12}\right.$ and $\left.C_{\max }\right)$ in children (study A) with those in healthy adults (study B) was performed. If there was a substantial overlap between the distributions of $\mathrm{AUC}_{0-12}$ in children and reference adults, and if the median $\mathrm{AUC}_{0-12}$ in children was similar to that in reference adults, the exposures were considered comparable. Analysis of the relationship between voriconazole exposure and safety endpoints (i.e., hepatic and visual AEs) in children was descriptive.

\section{RESULTS}

Subject disposition and demography. The demographic characteristics of children and reference adults are presented in Table 1.

(i) Study A (children). Forty subjects were enrolled from 11 of 16 centers and received IV voriconazole. Thirty-four subjects were able to switch to oral voriconazole, and 31 of them completed the study. There were 23 male subjects $(57.5 \%)$, and $60 \%$ of the subjects were less than 6 years old. The median (range) weight was 18.9 (10.8 to 54.5) kg. Twenty-seven $(67.5 \%)$ subjects had hematologic malignancies (17 subjects with leukemia, 5 with aplastic anemia, 2 with sickle cell anemia, 1 with congenital aplastic anemia, 1 with myelodysplastic syndrome, and 1 with myelofibrosis); 8 had neuroblastoma, and 5 had familial or genetic disorders which required stem cell transplant. The majority of subjects $(35 / 40,87.5 \%)$ had an HSCT prior to the start of study treatment or during the study.

Over $90 \%$ of the subjects (37/40) received voriconazole IV for 8 or more days, with a median (range) duration of 14 (4 to 36 ) days. More than $60 \%$ of the subjects (22/34) received oral
TABLE 1. Demographic characteristics of children (study A) and adults (study B)

\begin{tabular}{|c|c|c|}
\hline Characteristic & $\begin{array}{l}\text { Children } \\
(n=40)\end{array}$ & $\begin{array}{l}\text { Adults } \\
(n=35)\end{array}$ \\
\hline \multicolumn{3}{|l|}{ Gender (race) } \\
\hline $\begin{array}{l}\text { No. of males (no. of race } \\
\text { [white/black/other]) }\end{array}$ & $23(14 / 6 / 3)$ & $24(20 / 3 / 1)$ \\
\hline $\begin{array}{l}\text { No. of females (no. of race } \\
\text { [white/black/other]) }\end{array}$ & $17(10 / 5 / 2)$ & $11(10 / 0 / 1)$ \\
\hline \multicolumn{3}{|l|}{ Age } \\
\hline No. aged $2-<6$ yr & 24 & \\
\hline No. aged $6-<12$ yr & 16 & \\
\hline Mean age (yr) (SD) & $5.4(3.0)$ & $35.3(7.8)$ \\
\hline Median age (yr) (range) & $5.0(2-11)$ & $34(22-55)$ \\
\hline \multicolumn{3}{|l|}{ Wt } \\
\hline No. weighing $\leq 20 \mathrm{~kg}$ & 21 & \\
\hline No. weighing $>20 \mathrm{~kg}-\leq 40 \mathrm{~kg}$ & 13 & \\
\hline No. weighing $>40 \mathrm{~kg}$ & 6 & \\
\hline Mean wt (kg) (SD) & $22.9(12.2)$ & $75.1(11.2)$ \\
\hline Median wt (kg) (range) & $18.9(10.8-54.5)$ & $76.0(49.0-97.0)$ \\
\hline \multicolumn{3}{|l|}{$\begin{array}{l}\text { No. with CYP2C19 genotyping } \\
\text { status }^{a}\end{array}$} \\
\hline UM & 2 & \\
\hline EM & 11 & 20 \\
\hline HEM & 22 & 14 \\
\hline PM & 1 & 1 \\
\hline Unknown & 4 & \\
\hline
\end{tabular}

${ }^{a} \mathrm{UM}$, ultra rapid extensive metabolizer; EM, homozygous extensive metabolizer; HEM, heterozygous extensive metabolizer; PM, poor metabolizer.

voriconazole for 7 days, with a median (range) duration of 7 (7 to 20) days.

Most subjects $(37 / 40,92.5 \%)$ were taking at least one drug treatment prior to the start of study. All subjects took at least one drug treatment during the study. The most common concomitant medications taken prior to and during the study were antibacterial agents, immunosuppressants, and electrolyte replacements. Analgesics, antiviral agents, antihistamines, parenteral nutrition, and corticosteroids were also common. Except for one subject who inadvertently received esomeprazole throughout the study, the concomitant medications taken by study subjects had no known potential to affect voriconazole exposure.

(ii) Study B (reference adults). Thirty-five healthy subjects received voriconazole, and 32 of them completed the study. None of the discontinuations was considered related to the study drug.

Voriconazole pharmacokinetics in children compared to adults. Based on the visual inspection of voriconazole trough concentrations on day 4 through day 7 , the steady state was reached by day 7 for the IV and oral regimens in children. Intersubject variabilities for $\mathrm{AUC}_{0-12}$ and $C_{\max }$ in children appeared to be higher than those in adults (expressed as coefficient of variation [CV, as a percent] in Table 2).

(i) First IV dose on day 1. Voriconazole exposures $\left(\mathrm{AUC}_{0-12}\right.$ and $\left.C_{\max }\right)$ on day $1 \mathrm{IV}$ in children receiving a $7-\mathrm{mg} / \mathrm{kg}$ IV dose were generally lower than those in adults receiving a $6-\mathrm{mg} / \mathrm{kg}$ IV loading dose (Table 2 and Fig. 1). On average, $\mathrm{AUC}_{0-12}$ in children on day $1 \mathrm{IV}$ was approximately $44 \%$ lower than adults. However, a 5-year-old white female child (17.6 kg, a CYP2C19 
TABLE 2. Summary of plasma voriconazole pharmacokinetic parameters in children (study A) compared to adults (study B)

\begin{tabular}{|c|c|c|c|}
\hline \multirow{2}{*}{ Study group and parameter ${ }^{a}$} & \multicolumn{3}{|c|}{ Value for group at indicated dosage on: } \\
\hline & Day 1 , first IV dose & Day 7 of IV treatment (SS) & Day 7 of PO treatment (SS) \\
\hline Children $(n)$ & $7 \mathrm{mg} / \mathrm{kg}(33)$ & $7 \mathrm{mg} / \mathrm{kg}$ q12h (36) & 200 mg q12h (33) \\
\hline \multicolumn{4}{|l|}{$\operatorname{AUC}_{0-12}(\mu \mathrm{g} \cdot \mathrm{h} / \mathrm{ml})$} \\
\hline Geometric mean $(\mathrm{CV}, \%)$ & $7.85(71)$ & $21.4(110)$ & $18.6(134)$ \\
\hline Median (range) & $7.00(2.43-36.6)$ & $21.8(5.02-162)$ & $20.1(1.70-203)$ \\
\hline \multicolumn{4}{|l|}{$C_{\max }(\mu \mathrm{g} / \mathrm{ml})$} \\
\hline Geometric mean $(\mathrm{CV}, \%)$ & $2.15(47)$ & $4.26(71)$ & $3.62(87)$ \\
\hline Median (range) & $1.99(0.90-6.68)$ & $4.19(1.48-15.4)$ & $4.11(0.51-18.0)$ \\
\hline \multicolumn{4}{|l|}{$C_{\min }(\mu \mathrm{g} / \mathrm{ml})$} \\
\hline Geometric mean $(\mathrm{CV}, \%)$ & & $0.61(160)$ & $0.52(181)^{b}$ \\
\hline Median (range) & & $0.61(0.06-10.9)$ & $0.49(0.04-12.8)^{b}$ \\
\hline \multicolumn{4}{|l|}{$T_{\max }(\mathrm{h})$} \\
\hline Median (range) & $2.30(1.72-4.08)$ & $2.30(1.00-4.07)$ & $1.07(0.73-8.03)$ \\
\hline \multirow{2}{*}{\multicolumn{4}{|c|}{$\begin{array}{l}\text { Adults (reference) }(n) \\
\text { AUC }_{0-12}(\mu \mathrm{g} \cdot \mathrm{h} / \mathrm{ml})\end{array}$}} \\
\hline & & & \\
\hline Geometric mean $(\mathrm{CV}, \%)$ & $13.9(32)$ & $34.9(53)$ & $13.7(78)$ \\
\hline Median (range) & $13.3(7.43-29.7)$ & $37.6(13.7-104)$ & $12.8(4.89-61.6)$ \\
\hline \multicolumn{4}{|l|}{$C_{\max }(\mu \mathrm{g} / \mathrm{ml})$} \\
\hline Geometric mean $(\mathrm{CV}, \%)$ & $3.13(20)$ & $4.65(36)$ & $2.51(48)$ \\
\hline Median (range) & $3.05(2.08-4.88)$ & $4.60(2.48-9.92)$ & $2.45(1.23-6.84)$ \\
\hline \multicolumn{4}{|l|}{$C_{\min }(\mu \mathrm{g} / \mathrm{ml})$} \\
\hline Geometric mean $(\mathrm{CV}, \%)$ & & $1.78(72)$ & $0.51(119)$ \\
\hline Median (range) & & $2.08(0.38-7.35)$ & $0.46(0.14-4.27)$ \\
\hline \multicolumn{4}{|l|}{$T_{\max }(\mathrm{h})$} \\
\hline Median (range) & $1.97(1.97-1.97)$ & $1.3(1.3-1.3)$ & $1.0(1.0-2.0)$ \\
\hline
\end{tabular}

${ }^{a} \mathrm{AUC}_{0-12}$, area under the curve over 12-h dosing interval; $C_{\max }$, maximum plasma concentration; $C_{\min }$, minimum plasma concentration; $T_{\max }$, time to reach $C_{\max }$; SS, steady state.

${ }_{b} n=32$.

HEM) who inadvertently received daily IV administration of $20 \mathrm{mg}$ esomeprazole prior to study entry and throughout the study had the highest voriconazole exposure $\left(\mathrm{AUC}_{0-12}, 36.6\right.$ $\mu \mathrm{g} \cdot \mathrm{h} / \mathrm{ml})$ on day $1 \mathrm{IV}$. Esomeprazole, a known weak CYP2C19 inhibitor, may have reduced the metabolism of voriconazole in this subject.

(ii) Steady-state IV dosing regimen. Both geometric mean and median $\mathrm{AUC}_{0-12}$ in children receiving $7 \mathrm{mg} / \mathrm{kg}$ IV $\mathrm{q} 12 \mathrm{~h}$ were lower than those in adults receiving $4 \mathrm{mg} / \mathrm{kg}$ IV q12h (Table 2). Approximately $25 \%$ of children had exposures below the range observed in adults (Fig. 1). Nonetheless, there was a significant overlap of $\mathrm{AUC}_{0-12}$ distributions between children and adults due to larger intersubject variability in children. In addition, two children had very high voriconazole exposures, outside the range observed in adults.

Age, weight, and gender had no apparent effect on the voriconazole exposure in children receiving $7 \mathrm{mg} / \mathrm{kg}$ IV q12h (data on file).

(iii) Steady-state oral dosing regimen. At $200 \mathrm{mg}$ PO q12h, although the geometric mean and median $\mathrm{AUC}_{0-12}$ in children were higher than those in adults, the distribution of $\mathrm{AUC}_{0-12}$ in children was much wider than that in adults (Table 2 and Fig. 1). Several children exhibited very high and low exposures. There was a trend for the oral exposure $\left(\mathrm{AUC}_{0-12}\right)$ to decrease as weight or age increased in children, and intersubject variability in $\mathrm{AUC}_{0-12}$ also tended to decrease as age or weight increased (Fig. 2, top panel). When the 200-mg oral dose was converted to the $\mathrm{mg} / \mathrm{kg}$ scale based on each subject's body weight, a trend was observed: voriconazole exposure increased as the $\mathrm{mg} / \mathrm{kg}$ dose increased (Fig. 2c). It is noted that subjects with very high oral exposures received a relatively high dose, ranging from 13 to $18 \mathrm{mg} / \mathrm{kg}$. In addition, gender had no apparent effect on the oral exposure in children (Fig. 2d).

Correlation between voriconazole $\mathrm{AUC}_{\mathbf{0 - 1 2}}$ and $C_{\min } \cdot \mathrm{A}$ good correlation between voriconazole total exposures and trough concentrations at steady state was identified in children (Fig. 3) and adults (data on file). The linear regression equation for children's data is expressed as $\mathrm{AUC}_{0-12}=11.45+$ $14.97 \cdot C_{\min }\left(R^{2}=0.96\right)$, and that for adults' data is expressed as $\mathrm{AUC}_{0-12}=7.39+13.49 \cdot C_{\text {min }}\left(R^{2}=0.98\right)$.

Voriconazole exposure by CYP2C19 genotyping status. In study A, genotyping samples were collected from 36 of 40 children. There were 2 UMs, 11 EMs, 22 HEMs, and only one PM (an 8-year-old, 27.6-kg white male) (Table 1). This CYP2C19 PM subject provided exposure data only on day 1 IV $\left(\mathrm{AUC}_{0-12}, 11.0 \mu \mathrm{g} \cdot \mathrm{h} / \mathrm{ml} ; C_{\text {max }}: 2.56 \mu \mathrm{g} / \mathrm{ml} ; C_{\text {min }}: 0.27 \mu \mathrm{g} / \mathrm{ml}\right)$ and a trough concentration on day $4 \operatorname{IV}\left(C_{\min }, 2.28 \mu \mathrm{g} / \mathrm{ml}\right)$, which were slightly higher than the average exposures observed 

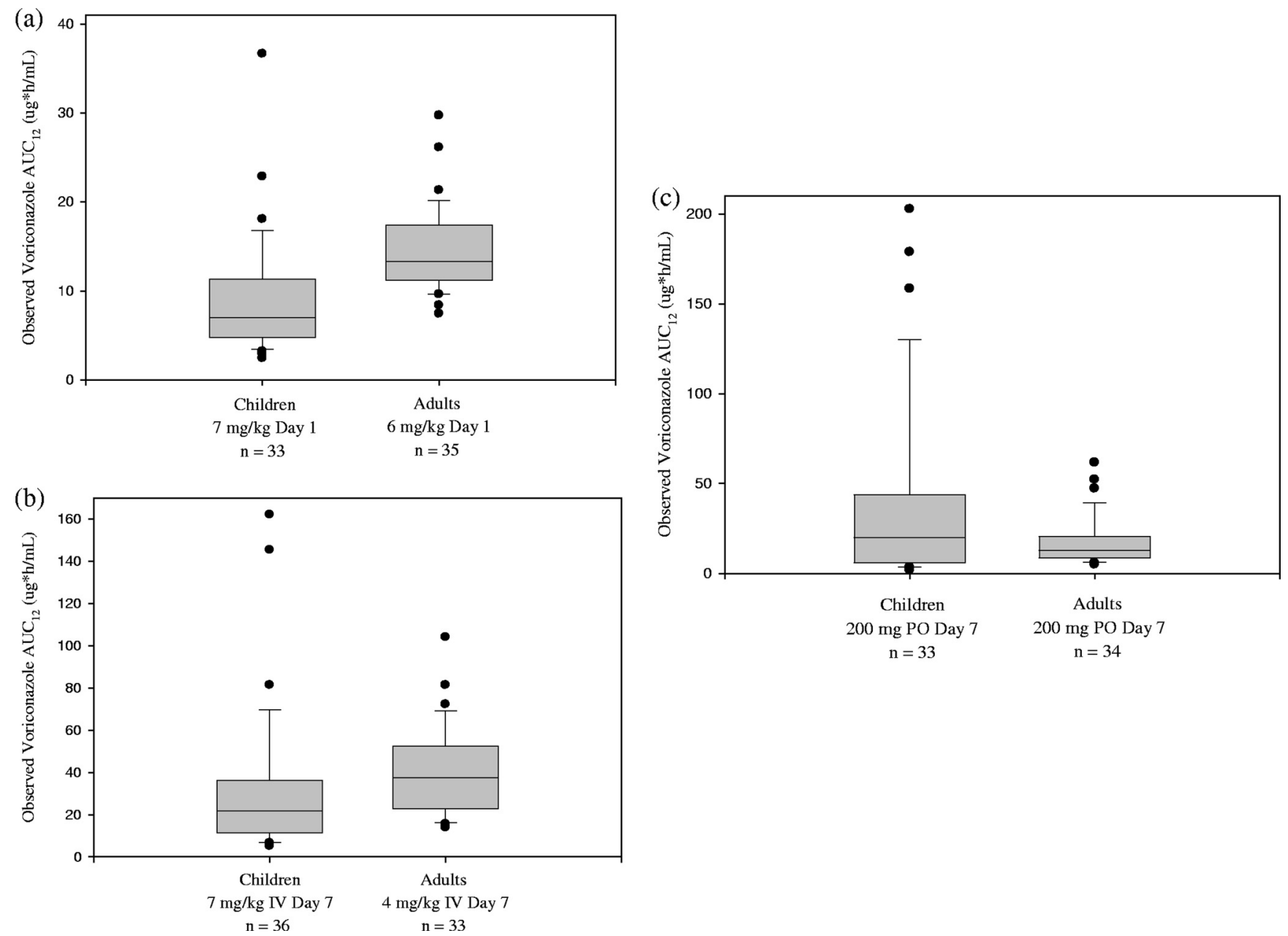

FIG. 1. Comparison of observed voriconazole $\mathrm{AUC}_{0-12}$ in children to those in adults on day 1 of IV treatment (a), day 7 of IV treatment (steady state) (b), and day 7 of oral treatment (steady state) (c). The box plot provides the median value with 10th, 25th, 75th, and 90th percentiles; values outside the 10th to 90 th percentiles are presented as solid circles.

in this study. The exposures in two CYP2C19 UMs were not at the lower end of distribution (e.g., $\mathrm{AUC}_{0-12}$ on day $1 \mathrm{IV}, 6.3$ and $10.9 \mu \mathrm{g} \cdot \mathrm{h} / \mathrm{ml}$; IV steady state, 11.9 and $60.8 \mu \mathrm{g} \cdot \mathrm{h} / \mathrm{ml}$ ). Although the median $\mathrm{AUC}_{0-12}$ in CYP2C19 HEM group was higher than that in the EM group, the distribution of $\mathrm{AUC}_{0-12}$ in the HEM group substantially overlapped with that in EM group. For example, at IV steady state, the median (range) $\mathrm{AUC}_{0-12}$ in CYP2C19 HEM and EM groups were 26.4 (6.47 to 162) $\mu \mathrm{g} \cdot \mathrm{h} / \mathrm{ml}$ and 14.8 (5.02 to 64.7$) \mu \mathrm{g} \cdot \mathrm{h} / \mathrm{ml}$, respectively. Overall, voriconazole exposure in children could not be predicted based on CYP2C19 genotype status in this study.

In study B, there was also one PM (a 28-year-old, 63-kg black male), and he had the highest exposure in adults (AUC $_{0-12}$ on day $1 \mathrm{IV}$, at IV steady state, and at oral steady state, 29.7, 104, and $61.1 \mu \mathrm{g} \cdot \mathrm{h} / \mathrm{ml}$, respectively).

Safety assessment in children. (i) Serious adverse events. No deaths were reported after the start of study treatment. Seventeen subjects experienced 30 serious adverse events (SAEs). The majority of events were attributed to the disease under study, concomitant drug therapy, or concurrent illness. The most commonly reported SAEs were fever (5 subjects), increased ALT (2 subjects), increased AST (2 subjects), cytomegalovirus infection (2 subjects), and graft-versus-host disease (2 subjects). Two SAEs (increased ALT and AST) experienced by one subject during the oral period were assessed as being related to voriconazole. Three SAEs (hypoxia, renal failure, and reversible posterior leukoencephalopathy syndrome) experienced by one subject during the IV and post-IV periods were assessed as being related to both voriconazole and cyclosporine (drug interaction which led to high concentrations of cyclosporine).

(ii) Discontinuations. Of the 9 subjects who discontinued the study, 4 discontinued for reasons related to voriconazole (all due to increases in liver function tests). Two subjects temporarily discontinued study treatment due to AEs: one was assessed as being related to methotrexate use, and the other (hypoxia, an SAE) was assessed as being related to both voriconazole and cyclosporine (drug interaction).

(iii) All-causality and treatment-related AEs. All 40 subjects experienced all-causality treatment-emergent AEs during the study, and most AEs were mild to moderate in severity. The most common treatment-emergent AEs, reported in at least 

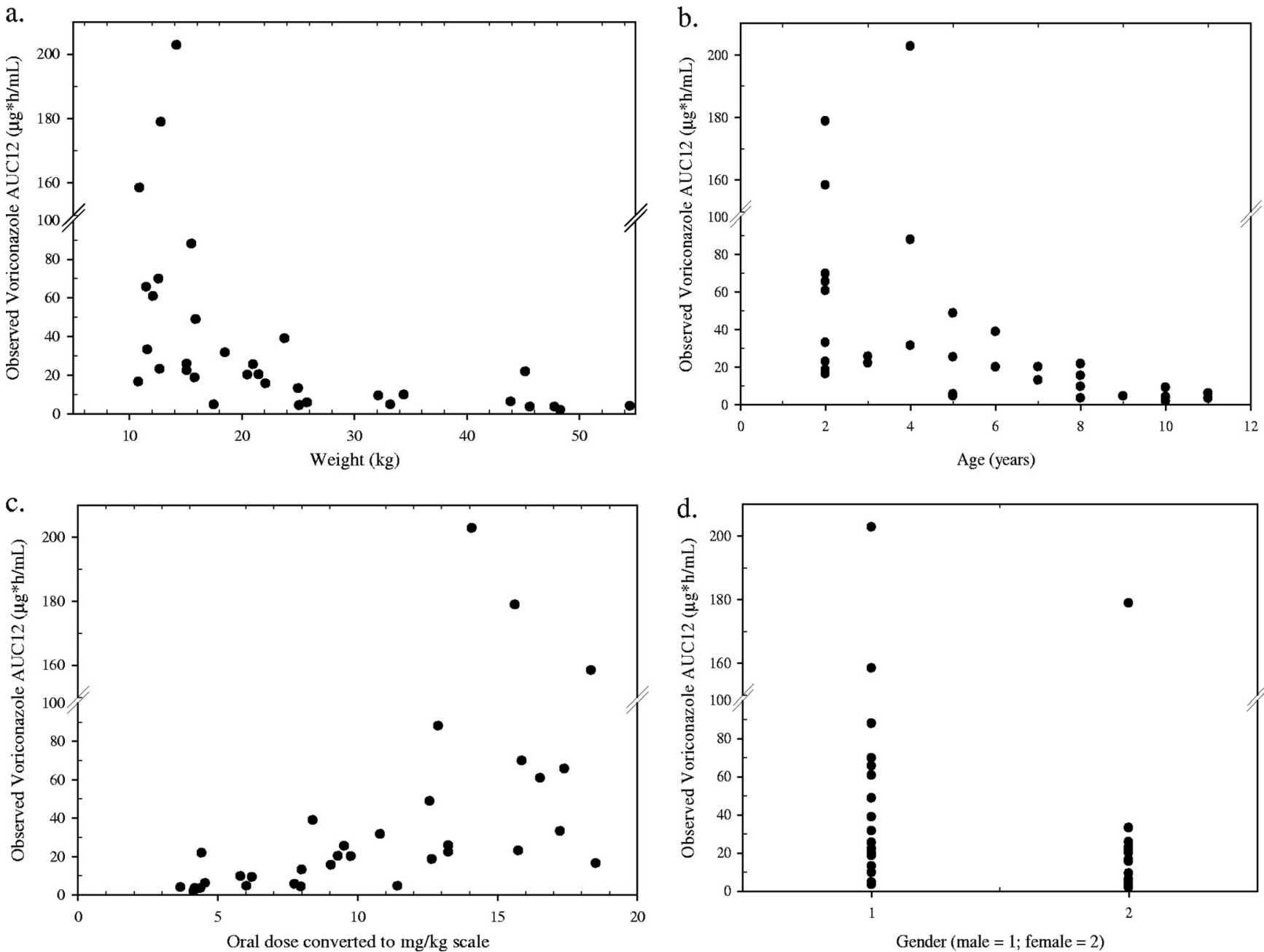

FIG. 2. Individual observed oral voriconazole $\mathrm{AUC}_{0-12}$ at steady state in children (200 $\mathrm{mg}$ orally q12h) by weight, age, dosing on a mg/kg basis, and gender.

$20 \%$ of subjects in either the IV or oral treatment period, were mucositis, fever, hypertension, pruritus, abdominal pain, rash, increased ALT, increased AST, alopecia, diarrhea, constipation, and fluid retention. These events were often related to accompanying illness and/or concomitant drug or nondrug treatments, and the pattern of these events was typical of those expected for subjects with immunosuppression and malignancies. Nine subjects experienced 31 treatment-related AEs, and the most common events were transient elevations of liver function tests.

(a) Hepatic adverse events. Twenty-six subjects experienced hepatobiliary disorders, and seven subjects experienced 13 treatment-related hepatic AEs.

(b) Visual adverse events. Twelve subjects experienced 18 events of eye disorders (e.g., dry eye, conjunctivitis). Among them, four subjects reported visual disturbances. Except for five mild visual events experienced by one subject, none of the eye disorders was assessed as being related to the study drug. The visual disturbances in three subjects assessed as being unrelated to study drug were blurred vision (scopolamine patch use), decreased visual acuity (distraction of the subject, posttreatment), and abnormal visual tracking test (presumed seizure and/or viral encephalitis, posttreatment) with blindness (adrenoleukodystrophy progression, posttreatment). The five visual events (change in color vision, reduced visual acuity, astigmatism, decreased lacrimation, and myopia) experienced by a 7-year-old white male were assessed as being related to the study drug, since the investigator could not rule out the possibility that these events were related to the study drug. The change in color vision (red-green deficiency of the protan type, day 7 of IV treatment) was resolved 6 days later (day 13 of IV treatment). The reduced visual acuity was resolved on the next day (day 2 of oral treatment).

(iv) ECGs. Because of the high heart rate in pediatric patients, Fridericia's correction of the QT interval (QTcF) was thought to provide a better estimation than Bazett's correction (QTcB). The mean changes from baseline in QTcF after 7 days of IV and oral voriconazole were 3.0 and $4.2 \mathrm{~ms}$, respectively. One subject developed a borderline QT prolongation that was considered clinically significant but unrelated to the study drug by the local cardiologist. None of the 

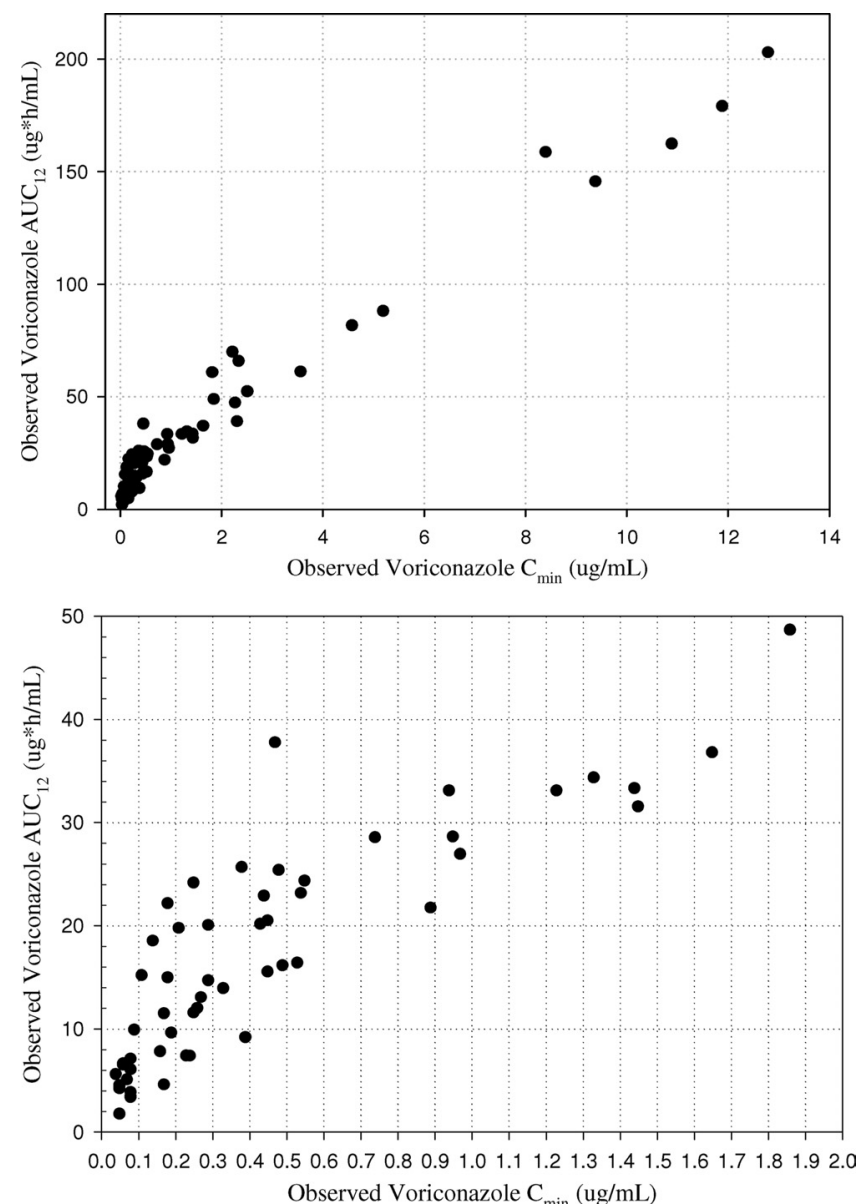

FIG. 3. Observed voriconazole $\mathrm{AUC}_{0-12}$ versus $C_{\min }$ at steady state in children receiving $7 \mathrm{mg} / \mathrm{kg} \mathrm{IV} \mathrm{q12h}$ and $200 \mathrm{mg}$ orally q12h (top, all subjects; bottom, subset of subjects with $C_{\min }$ of $<2 \mu \mathrm{g} / \mathrm{ml}$ ). other changes in ECG was considered clinically significant relative to the baseline.

Relationship between voriconazole exposure and hepatic and visual events in children. For hepatic AEs assessed as being unrelated to the study drug, the corresponding voriconazole exposures ranged from 5 to $203 \mu \mathrm{g} \cdot \mathrm{h} / \mathrm{ml}$ (Table 3). For treatment-related hepatic AEs, the corresponding exposures ranged from 33 to $203 \mu \mathrm{g} \cdot \mathrm{h} / \mathrm{ml}$ (Table 4), which were higher than the average exposures observed in this study $\left(\mathrm{AUC}_{0-12}\right.$ for IV and oral treatments, $21.4 \mu \mathrm{g} \cdot \mathrm{h} / \mathrm{ml}$ and $18.6 \mu \mathrm{g} \cdot \mathrm{h} / \mathrm{ml}$ ). If only the treatment-related hepatic AEs were considered, there appeared to be a positive association between exposure and hepatic AEs. However, four of six children with very high voriconazole exposures $\left(\mathrm{AUC}_{0-12}>80 \mu \mathrm{g} \cdot \mathrm{h} / \mathrm{ml}\right)$ tolerated voriconazole without any hepatic AEs (Table 5). Although treatment-related hepatic AEs led to four discontinuations, voriconazole exposures $\left(\mathrm{AUC}_{0-12 \text { : }}\right.$ of approximately 30 to 50 $\mu \mathrm{g} \cdot \mathrm{h} / \mathrm{ml})$ in these subjects were not among the highest in children (Table 4). In addition, although the subject with the highest voriconazole exposure $\left(\mathrm{AUC}_{0-12}\right.$ for oral treatment, $203 \mu \mathrm{g} \cdot \mathrm{h} / \mathrm{ml}$ ) experienced treatment-related severe elevations of ALT and AST (reported as SAEs) on oral-treatment day 5, these events were resolved on oral-treatment day 10 without any alteration of study drug treatment (Table 5). Hence, there was no clear threshold of voriconazole exposure that would predict the occurrence of treatment-related hepatic AEs.

The subject (a 7-year-old white male) with five treatmentrelated visual AEs had voriconazole exposures similar to or below the average exposures in this study (Table 4), indicating no apparent relationship between voriconazole exposures and visual events.

\section{DISCUSSION}

A comparison of the child and adult exposure data revealed that the previously proposed pediatric dosing regimens based

TABLE 3. Hepatic adverse events (unrelated to study drug) versus corresponding observed voriconazole exposure parameters in children ${ }^{a}$

\begin{tabular}{|c|c|c|c|c|c|c|}
\hline Subject & $\begin{array}{l}\text { Hepatic adverse event(s) } \\
\text { (unrelated to study drug) }\end{array}$ & $\begin{array}{l}\text { AE onset } \\
\text { study day }\end{array}$ & $\begin{array}{l}\text { Treatment } \\
\text { period }\end{array}$ & $\begin{array}{c}\mathrm{AUC}_{0-12} \\
(\mu \mathrm{g} \cdot \mathrm{h} / \mathrm{ml})\end{array}$ & $\begin{array}{c}C_{\max } \\
(\mu \mathrm{g} / \mathrm{ml})\end{array}$ & $\underset{(\mu \mathrm{g} / \mathrm{ml})}{C_{\min }}$ \\
\hline 5 & Hyperbilirubinemia & 9 & IV & 14.9 & 4.09 & 0.18 \\
\hline 6 & Hyperbilirubinemia & 12 & IV & 60.8 & 7.72 & 3.57 \\
\hline 7 & Hyperbilirubinemia & 12 & IV & 7.33 & 1.82 & 0.23 \\
\hline 10 & Hepatomegaly, hyperbilirubinemia & 8 & IV & 24.1 & 3.73 & 0.25 \\
\hline 14 & Hyperbilirubinaemia & 19 & IV & 5.02 & 1.63 & 0.07 \\
\hline 21 & Decreased hepatic enzyme & 9 & IV & 26.9 & 4.04 & 0.97 \\
\hline 23 & Hepatomegaly, increased ALT & 29 & IV & 7.32 & 2.44 & 0.24 \\
\hline 25 & Increased ALT, AST, and GGT; hepatosplenomegaly & 18 & IV & 16.1 & 3.67 & 0.49 \\
\hline 27 & Increased AST & 49 & Oral & 16.3 & 2.86 & 0.53 \\
\hline 28 & Increased GGT & 19 & Oral & 60.6 & 8.44 & 1.83 \\
\hline 29 & Increased ALT, AST, and GGT & 13 & Oral & 69.6 & 10.7 & 2.23 \\
\hline
\end{tabular}

${ }^{a} \mathrm{AE}$, adverse event; GGT, gamma glutamyltransferase; ALT, alanine aminotransferase; AST, aspartate aminotransferase. Two subjects with hepatic events were excluded due to lack of corresponding exposure parameters. Steady-state IV and oral voriconazole exposures were used as the estimates for AEs that occurred on nonpharmacokinetic days. 
TABLE 4. Hepatic and visual adverse events (related to study drug) versus corresponding observed voriconazole exposure parameters in children $^{a}$

\begin{tabular}{|c|c|c|c|c|c|c|}
\hline $\begin{array}{l}\text { Event type } \\
\text { and subject }\end{array}$ & $\begin{array}{l}\text { Adverse events } \\
\text { (related to study drug) }\end{array}$ & AE onset study day & Period & $\begin{array}{l}\mathrm{AUC}_{0-12} \\
(\mu \mathrm{g} \cdot \mathrm{h} / \mathrm{ml})\end{array}$ & $\underset{(\mu \mathrm{g} / \mathrm{ml})}{C_{\max }}$ & $\underset{(\mu \mathrm{g} / \mathrm{ml})}{C_{\min }}$ \\
\hline \multicolumn{7}{|l|}{ Hepatic } \\
\hline $17^{b, c}$ & Severe hyperbilirubinemia & 8 & IV & 34.3 & 5.81 & 1.33 \\
\hline $19^{b}$ & Moderate increase in hepatic enzyme & 6 & IV & 33.0 & 4.30 & 0.94 \\
\hline $24^{b}$ & Mild hepatomegaly; severe increase in hepatic enzyme & 18 & IV & 36.7 & 5.66 & 1.65 \\
\hline 26 & Mild increase in transaminases & 22 & IV & 52.0 & 7.52 & 2.52 \\
\hline $30^{b, d}$ & Severe increase in ALT; moderate increase in AST & 3 & IV & & & 2.28 \\
\hline 32 & Mild increases in ALT and AST & 6 & IV & 81.4 & 9.71 & 4.59 \\
\hline 32 & Mild increase in GGT & 14 (day 7 of oral treatment) & Oral & 48.6 & 7.39 & 1.86 \\
\hline $33^{e}$ & Severe increases in ALT and AST & 11 (day 5 of oral treatment) & Oral & 203 & 18.0 & 12.8 \\
\hline \multicolumn{7}{|l|}{ Visual } \\
\hline \multirow[t]{3}{*}{38} & Mild change in color vision & 7 & IV & 11.4 & 2.35 & 0.17 \\
\hline & Mild reduction in visual acuity & 20 (day 1 of oral treatment) & Oral & & & \\
\hline & $\begin{array}{l}\text { Mild astigmatism, mild myopia, mild lacrimation } \\
\text { decrease }\end{array}$ & 24 (day 4 of oral treatment) & Oral & 20.1 & 4.53 & 0.43 \\
\hline
\end{tabular}

\footnotetext{
${ }^{a}$ Steady-state IV and oral voriconazole exposures were used as the estimates for AEs that occurred on nonpharmacokinetic days.

${ }^{b}$ Adverse event(s) resulted in permanent discontinuation.

${ }^{c}$ This subject received esomeprazole throughout the study.

${ }^{d}$ This subject was the CYP2C19 PM, who discontinued on day 4, and these events were resolved on days 5 and 6 .

${ }^{e}$ These events were also reported as serious AEs, which were resolved on oral treatment day 10 without any alteration of the study drug.

${ }^{f}$ ALT, alanine aminotransferase; AST, aspartate aminotransfearse; GGT, gamma glutamyltransferase.
}

on population pharmacokinetic modeling and simulation need to be further modified.

The majority of children after the first $7-\mathrm{mg} / \mathrm{kg}$ IV dose had lower voriconazole exposure than the range observed in adults after a $6-\mathrm{mg} / \mathrm{kg}$ IV loading dose. This suggested that children need to receive a dose higher than $7 \mathrm{mg} / \mathrm{kg}$ IV on the first day in order to closely match the exposure in adults.

At steady state for IV treatment ( $7 \mathrm{mg} / \mathrm{kg}$ IV q12h), although there was a significant overlap of $\mathrm{AUC}_{0-12}$ distributions, approximately $25 \%$ of children had lower exposures than the range observed in adults receiving $4 \mathrm{mg} / \mathrm{kg}$ IV q12h. On average, $\mathrm{AUC}_{0-12}$ in children was $21 \mu \mathrm{g} \cdot \mathrm{h} / \mathrm{ml}$, which was approximately $40 \%$ lower than that in adults $\left(\mathrm{AUC}_{0-12}, 35\right.$ $\mu \mathrm{g} \cdot \mathrm{h} / \mathrm{ml})$. Considering the life-threatening nature of invasive fungal infections, a higher IV maintenance dose than $7 \mathrm{mg} / \mathrm{kg}$ may need to be considered to ensure that the majority of children reach adequate voriconazole levels at the early stage of treatment. In the meantime, it should be recognized that some children may experience much higher voriconazole exposure due to large intersubject variability. Therefore, close monitoring of adverse events is warranted, and flexible dose adjustment should be considered for children in clinical practice.

At steady state for oral treatment (200 mg PO q12h), voriconazole exposure $\left(\mathrm{AUC}_{0-12}\right)$ decreased as body weight or age increased in children, indicating that fixed oral dosing is not an ideal approach. Since the previous modeling work was based on data obtained with low oral doses (4 and $6 \mathrm{mg} / \mathrm{kg}$ PO q12h), it was speculated that oral bioavailability of voriconazole decreased as weight decreased and higher weight-based doses would be needed in younger children with low body weight (7). Hence, the fixed oral dose was proposed at that time. A wide range of weight-based oral doses (3.5 to $18.5 \mathrm{mg} / \mathrm{kg}$, based on the conversion of a 200-mg fixed dose) was evaluated in this study, which provided more information to help refine the oral dose in children. Based on the preliminary evaluation of the observed data, the traditional weight-based dosing may be an appropriate approach for children to match $200 \mathrm{mg}$ PO q12h in adults.

To optimize the pediatric dosing regimens matching the

TABLE 5. Treatment-related adverse events versus corresponding observed voriconazole exposure parameters in children with high exposures ${ }^{a}$

\begin{tabular}{|c|c|c|c|c|c|c|}
\hline Subject $^{b}$ & Adverse event(s) ${ }^{c}$ & AE onset study day & Period & $\begin{array}{c}\mathrm{AUC}_{0-12} \\
(\mu \mathrm{g} \cdot \mathrm{h} / \mathrm{ml})\end{array}$ & $\begin{array}{c}C_{\max } \\
(\mu \mathrm{g} / \mathrm{ml})\end{array}$ & $\begin{array}{c}C_{\min } \\
(\mu \mathrm{g} / \mathrm{ml})\end{array}$ \\
\hline $34(8, F, 45.2)$ & Hypoxia & 10 & IV & 162 & 14.9 & 10.9 \\
\hline $39(2, \mathrm{~F}, 12.8)$ & None & & IV & 145 & 15.4 & 9.39 \\
\hline $32(5, \mathrm{M}, 15.9)$ & Increased ALT and AST & 7 & IV & 81.4 & 9.70 & 4.59 \\
\hline $33(4, \mathrm{M}, 14.2)$ & Increased ALT and $\mathrm{AST}^{d}$ & 11 (day 5 of oral treatment) & Oral & 203 & 18.0 & 12.8 \\
\hline $39(2, F, 12.8)$ & None & & Oral & 179 & 18.0 & 11.9 \\
\hline $3(2, \mathrm{M}, 10.9)$ & None & & Oral & 158 & 14.6 & 8.41 \\
\hline $37(4, \mathrm{M}, 15.5)$ & None & & Oral & 87.8 & 10.1 & 5.20 \\
\hline
\end{tabular}

${ }^{a}$ Each subject received voriconazole at $7 \mathrm{mg} / \mathrm{kg}$ IV q12h followed by $200 \mathrm{mg}$ PO q12h.

${ }^{b}$ Data are age (years), sex, and weight (kilograms). All children were classified by CYP2C19 genotype as HEMs.

${ }^{c}$ IV, intravenous, ALT, alanine aminotransferase, AST, aspartate aminotransferase.

${ }^{d}$ These events resolved on day 10 oral without any alteration of study drug treatment. 
adult exposures, an integrated population pharmacokinetic modeling and simulation was performed based on the pooled data from these two studies (A and B) as well as three other pediatric pharmacokinetic studies, and the detailed results are being presented separately (L. E. Friberg, P. Ravva, M. O. Karlsson and P. Liu, submitted for publication).

Michael's group also evaluated voriconazole pharmacokinetics of $7 \mathrm{mg} / \mathrm{kg}$ IV q12h (on day 3) in nine immunocompromised children (8). In that study, the geometric mean (range) $\mathrm{AUC}_{0-12}$ was 49.3 (4.7 to 106.6$) \mu \mathrm{g} \cdot \mathrm{h} / \mathrm{ml}$, which had a higher average value but a similar range compared with this study. The higher average exposure may be partially explained by the concomitant use of esomeprazole in six children. As noted earlier, esomeprazole could increase voriconazole exposure. Although no studies directly evaluated the interaction between voriconazole and esomeprazole, the interaction between voriconazole and omeprazole (similar to esomeprazole) showed that the voriconazole $\mathrm{AUC}_{0-12}$ was increased by approximately $40 \%$ (17). This modest increase does not warrant an adjustment of the voriconazole dose, but the concomitant use of these medications will compromise the accuracy of the estimation of voriconazole exposure from pharmacokinetic perspective. Michael's group also reported a much higher geometric mean $C_{\max }(11.4 \mu \mathrm{g} / \mathrm{ml})$, which can be explained by the different infusion times used ( 1 versus $2.3 \mathrm{~h}$ ). Our study used the infusion rate $(3 \mathrm{mg} / \mathrm{kg} / \mathrm{h})$ recommended in the label instructions to minimize any potential infusion-related reactions and avoid very high peak concentrations (12).

This study was conducted in a patient population that was restricted from receiving CYP450 inhibitors or inducers. It should be noted that drug-drug interaction is one of the major extrinsic factors contributing to the intra- and intersubject variability in voriconazole exposure in the clinical setting, which affects the prediction of exposure at a given dose. Therefore, concomitant medications used in a specific patient when initiating voriconazole therapy or during the therapy should be taken into consideration for voriconazole dosing management.

It was not unexpected that CYP2C19 status was not predictive of voriconazole exposure in immunocompromised children in this study. Since other factors (e.g., use of concomitant medications, subject's underlying condition) also contribute to the intersubject variability in voriconazole exposure, the significance of CYP2C19 status could be diminished in the clinical setting.

Although a clear correlation between voriconazole exposure and clinical efficacy has not been established (12), it is appropriate to maintain voriconazole exposure at adequate levels to treat fungal infections. The good correlation between $\mathrm{AUC}_{0-12}$ and $C_{\min }$ at steady state will allow rough estimation of voriconazole total exposure based on the trough concentration only. Several proposals for voriconazole trough concentrations based on retrospective analyses have been made (e.g., $0.5,1$ or $2 \mu \mathrm{g} / \mathrm{ml}$ as the lower limit; 5.5 to $6 \mu \mathrm{g} / \mathrm{ml}$ as the upper limit) (3, $9,10,13,14)$. This remains to be confirmed in future studies.

Since children have faster metabolism of voriconazole than adults, children have lower accumulation of voriconazole, and the elimination phase in children is steeper than that in adults. For the same voriconazole total exposure, the corresponding trough concentration in children is expected to be lower than that in adults. For instance, based on the correlation equations for $\mathrm{AUC}_{0-12}$ and $C_{\text {min }}$, with a target $\mathrm{AUC}_{0-12}$ of $15 \mu \mathrm{g} \cdot \mathrm{h} / \mathrm{ml}$, the corresponding $C_{\min }$ in children and adults are approximately 0.24 and $0.56 \mu \mathrm{g} / \mathrm{ml}$, respectively. With a target $\mathrm{AUC}_{0-12}$ of $20 \mu \mathrm{g} \cdot \mathrm{h} / \mathrm{ml}$, the corresponding $C_{\text {min }}$ in children and adults are approximately 0.57 and $0.93 \mu \mathrm{g} / \mathrm{ml}$, respectively. Also, as shown in Fig. 3, when the voriconazole $C_{\text {min }}$ exceeded $1 \mu \mathrm{g} / \mathrm{ml}$ in children, all corresponding $\mathrm{AUC}_{0-12}$ values were above $30 \mu \mathrm{g} \cdot \mathrm{h} / \mathrm{ml}$, while the $\mathrm{AUC}_{0-12}$ in adults was approximately $21 \mu \mathrm{g} \cdot \mathrm{h} / \mathrm{ml}$ at a $C_{\min }$ of $1 \mu \mathrm{g} / \mathrm{ml}$. With a target $\mathrm{AUC}_{0-12}$ of $100 \mu \mathrm{g} \cdot \mathrm{h} / \mathrm{ml}$, the corresponding $C_{\text {min }}$ in children and adults are approximately 6 and $7 \mu \mathrm{g} / \mathrm{ml}$, respectively.

One observation from previous studies is worth noting: the collection time for trough samples had very large variation. As stated in the study by Neely et al. (9), the median sampling time for 108 samples in 40 patients was $9.0 \mathrm{~h}$ postdose, ranging from 1.3 to $36 \mathrm{~h}$, which was a reflection of the clinical practice of monitoring trough samples. In theory, a trough (12 h postdose, just prior to the next dose) sample provides the lowest concentration over the dosing interval. When other time points instead of the real trough are used, the estimation of trough levels will certainly be inflated. If prescribers choose to use trough concentrations to guide voriconazole dose adjustment in addition to monitoring of AEs and patients' responses, the trough sample should be collected between 11 and $12 \mathrm{~h}$ postdose. Considering the challenges in clinical logistics, the sampling window could be extended to 10 to $12 \mathrm{~h}$ postdose. If a sample is collected outside this window, it should not be counted as a trough sample.

In this study, two children (CYP2C19 HEM) received oral voriconazole (200 mg PO q12h) by nasogastric tubing due to serious mucositis. A 2-year-old, 12.8-kg black female had an $\mathrm{AUC}_{0-12}$ of $179 \mu \mathrm{g} \cdot \mathrm{h} / \mathrm{ml}$, and a 7-year-old, 21.5-kg white male had an $\mathrm{AUC}_{0-12}$ of $20.1 \mu \mathrm{g} \cdot \mathrm{h} / \mathrm{ml}$. There was no apparent difference between these subjects and other subjects in a similar age and weight range (Fig. 2).

The safety and tolerability of voriconazole in children from this study, in terms of hepatic, visual, and cardiac events and laboratory abnormalities, were consistent with the known safety profile of voriconazole in adults (12). Where differences in the reporting frequencies of $\mathrm{AE}$ terms were noted between children and adults, these could be explained by subjects' underlying conditions or concomitant treatment (e.g., mucositis, hypertension, and alopecia).

As described above, there was no apparent association between voriconazole exposure and hepatic and visual AEs in children and no clear threshold of exposure that would predict the occurrence of treatment-related hepatic AEs. Similar findings in children were also reported previously, showing no strong correlation between voriconazole exposure and hepatotoxicity or abnormal liver function tests $(8,9)$.

In summary, voriconazole IV doses higher than $7 \mathrm{mg} / \mathrm{kg}$ are needed in children to closely match the adult exposures of currently recommended regimens (i.e., $6 \rightarrow 4 \mathrm{mg} / \mathrm{kg}$ IV q12h). A weight-based oral dose may be more appropriate for children than a fixed oral dose to match the adult exposure at 200 mg PO q12h. Gender and CYP2C19 genotype had no apparent effect on the voriconazole exposure in children. The safety and tolerability of voriconazole in children during both IV and oral administration were consistent with the known safety profile of voriconazole. 


\section{ACKNOWLEDGMENTS}

We sincerely thank all the clinical staff from 11 pediatric study centers in the United States for their outstanding support and dedication to this pediatric study (Duke University Medical Center, Durham, NC; Children's Hosp/LSUHSC, New Orleans, LA; Vanderbilt University Medical Center, Nashville, TN; Texas Children's Hospital, Houston, TX; Doernbecher Children's Hospital, Portland, OR; University Hospital Case Medical Center, Cleveland, OH; Children's Hospital Orange County, Orange, CA; University Arizona Health Science Center, Tucson, AZ; Nemours Children's Clinic, Jacksonville, FL; Emory Children's Center, Atlanta, GA; and Herman and Walter Samuelson Children's Hospital at Sinai, Baltimore, MD). We thank our study team at Pfizer, who contributed to the protocol and study. We also thank our assay specialist, Tanja Alebic-Kolbah, and PPD Development (Richmond, VA) for the analytical assay support.

This study was sponsored by Pfizer. P. Liu is an employee of Pfizer, A. Baruch was an employee of Pfizer when the study was conducted, and the other authors were the principal investigators for this pediatric study.

\section{REFERENCES}

1. Andrews, E., et al. 2008. Pharmacokinetics and tolerability of voriconazole and a combination oral contraceptive co-administered in healthy female subjects. Br. J. Clin. Pharmacol. 65:531-539.

2. Clancy, C. J., and M. H. Nguyen. 1998. In vitro efficacy and fungicidal activity of voriconazole against Aspergillus and Fusarium species. Eur. J. Clin. Microbiol. Infect. Dis. 17:573-575.

3. Denning, D. W., et al. 2002. Efficacy and safety of voriconazole in the treatment of acute invasive aspergillosis. Clin. Infect. Dis. 34:563-571.

4. Espinel-Ingroff, A. 1998. In vitro activity of the new triazole voriconazole (UK-109,496) against opportunistic filamentous and dimorphic fungi and common and emerging yeast pathogens. J. Clin. Microbiol. 36:198-202.
5. Espinel-Ingroff, A., K. Boyle, and D. J. Sheehan. 2001. In vitro antifungal activities of voriconazole and reference agents as determined by NCCLS methods: review of the literature. Mycopathologia 150:101-115.

6. Herbrecht, R., et al. 2002. Voriconazole versus amphotericin B for primary therapy of invasive aspergillosis. N. Engl. J. Med. 347:408-415.

7. Karlsson, M. O., I. Lutsar, and P. A. Milligan. 2009. Population pharmacokinetic analysis of voriconazole plasma concentration data from pediatric studies. Antimicrob. Agents Chemother. 53:935-944.

8. Michael, C., et al. 2010. Voriconazole pharmacokinetics and safety in immunocompromised children compared to adult patients. Antimicrob. Agents Chemother. 54:3225-3232.

9. Neely, M., T. Rushing, A. Kovacs, R. Jelliffe, and J. Hoffman. 2010. Voriconazole pharmacokinetics and pharmacodynamics in children. Clin. Infect. Dis. 50:27-36.

10. Pascual, A., et al. 2008. Voriconazole therapeutic drug monitoring in patients with invasive mycoses improves efficacy and safety outcomes. Clin. Infect. Dis. 46:201-211.

11. Perfect, J. R., et al. 2003. Voriconazole treatment for less-common, emerging, or refractory fungal infections. Clin. Infect. Dis. 36:1122-1131.

12. Pfizer Inc. 2010. VFEND ${ }^{\circledR}$ (voriconazole) United States package insert. Pfizer Inc., New York, NY.

13. Smith, J., and D. Andes. 2008. Therapeutic drug monitoring of antifungals: pharmacokinetic and pharmacodynamic considerations. Ther. Drug Monit. 30:167-172.

14. Smith, J., et al. 2006. Voriconazole therapeutic drug monitoring. Antimicrob. Agents Chemother. 50:1570-1572.

15. Walsh, T. J., et al. 2010. Pharmacokinetics, safety, and tolerability of voriconazole in immunocompromised children. Antimicrob. Agents Chemother. 54:4116-4123.

16. Walsh, T. J., et al. 2004. Pharmacokinetics and safety of intravenous voriconazole in children after single- or multiple-dose administration. Antimicrob. Agents Chemother. 48:2166-2172.

17. Wood, N., et al. 2003. Effect of omeprazole on the steady-state pharmacokinetics of voriconazole. Br. J. Clin. Pharmacol. 56(Suppl. 1):56-61. 